\title{
The diet of brown hyaenas (Hyaena brunnea) in Shamwari Game Reserve, Eastern Cape, South Africa
}

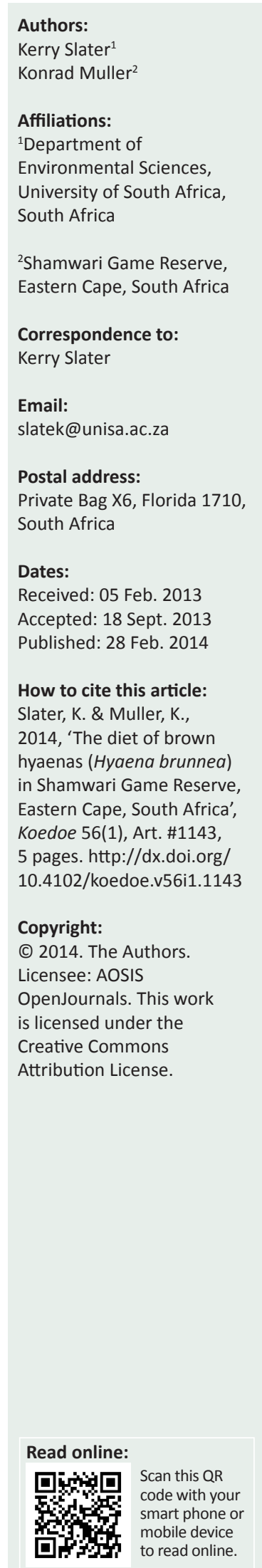

Brown hyaenas (Hyaena brunnea) were introduced to Shamwari Game Reserve in the Eastern Cape Province during 2002, but their feeding ecology is poorly understood. Feeding observations of brown hyaena by field guides and the collection of 31 scats from the study area took place over an 11 month period. Standard techniques were used to analyse the scats and identify prey items present. Ten dietary categories were identified from the scats, with a mean of 3.2 dietary categories per scat. Large mammal remains were found in 30 of the 31 scats, with kudu being the most abundant (61.0\% of scats). Overall the two methods indicated at least 14 mammal species being fed on by the brown hyaena. The presence of mainly large mammal remains and invertebrates (in $38.7 \%$ of all scats), together with the feeding observations of mainly large mammals by field guides, suggests that brown hyaena in Shamwari are mainly scavengers and that sufficient carrion is available, thereby reducing the need for them to hunt. A $52.0 \%$ occurrence of plant matter was found in the scats, suggesting that plant material is an important component of their diet. Further studies are underway to investigate the feeding ecology of brown hyaena in Shamwari and surrounding areas.

Conservation implications: Comprehensive scat analysis over a number of years, monitoring of individual movement patterns and population numbers of brown hyaena in and around conservation areas will be beneficial in quantifying resource use of this species.

\section{Introduction}

Investigating the diet of free-ranging animals provides information of resources available to and utilised by these animals, but this information is not always available to wildlife area managers because of constraints on time-consuming field work. The diet of a carnivore is a reflection of its feeding type (specialist or opportunistic), the availability of its potential prey and its morphological, behavioural and physiological adaptations (Kok \& Nel 2004).

Previous studies on brown hyaenas (Hyaena brunnea) have shown it to have a diverse diet and, although primarily a scavenger of mammals, it also forages for insects, reptiles, birds and their eggs, and plants (Burgener \& Gusset 2003; Kuhn, Wiesel \& Skinner 2008; Maude 2005; Mills \& Mills 1978; Owens \& Owens 1978; Skinner 1976; Skinner \& Chimimba 2005; Skinner \& Van Aarde 1981; Van der Merwe et al. 2009). Despite being generalist feeders, they appear to lean towards specific prey items depending on their habitat. For example, in the southern Kalahari, 58 different food types were identified in faecal samples (Mills \& Mills 1978), but along the Namib Desert coast, the bulk of the brown hyaena's diet is Cape fur seals (Arctocephalus pusillus) (Goss 1986; Kuhn et al. 2008; Siegfried 1984; Skinner \& Van Aarde 1981). Brown hyaenas are inefficient predators and food obtained by hunting is rare (Mills \& Mills 1978). In the southern Kalahari, only $4.7 \%$ of hunting attempts were successful and those vertebrates hunted successfully made up only $4.2 \%$ of the total vertebrate diet (Mills 1978). Vertebrates hunted were also of small sizes and included birds such as korhaan (Eupodotis sp.), small mammals such as springbok lamb (Antidorcus marsupilis), springhare (Pedetes capensis), striped polecat (Ictonyx striatus) and bateared fox (Otocyon megalotis) (Mills 1990). Along the Namib coast, between 2.9\% (Goss 1986) and 9.6\% (Wiesel 2010) of the Cape fur seal pups eaten were killed by the brown hyaenas themselves. In areas where brown hyaena ranges overlap with agricultural lands (Skinner 1976; Skinner \& Van Aarde 1981) or human settlements (Kuhn et al. 2008), remains of domestic dogs, cats, cattle, goats, sheep, horses and donkeys (Maude 2005) have been found in their faecal scats.

Brown hyaenas are sparsely distributed over the arid and semi-arid regions of southern Africa (Mills \& Hofer 1998). Owing to the shy behaviour of this animal, only a handful of papers report on their diet and are mainly restricted to arid areas. There is therefore generally a lack of this information in most of their distribution range.

During the early 1990s, the Eastern Cape Province transformed large areas of agriculture to more economically viable game farming, ecotourism and conservation areas (Hayward et al. 2007). This change in land use led to numerous wildlife species being reintroduced to former domestic 
livestock farms. These reintroductions included large predator species that had historically occurred in the eastern Cape region, with the main aim of these reintroductions being to restore ecological integrity, conserve threatened species and maximise ecotourism (Hayward et al. 2007). Although translocation of large carnivores is common, there is often very little or no post-release monitoring (Hofmeyer \& Van Dyk 1998).

\section{Research method and design \\ Study area}

This article describes a preliminary study on the diet of brown hyaenas at Shamwari Game Reserve in South Africa's

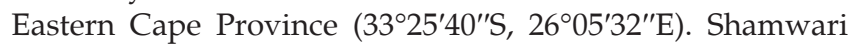
is approximately 25000 ha, traversing four geological formations (i.e. Bokkeveld series shale, Witteberg quartzite, Karoo sandstone and Sundays River formations) (O'Brien 2004). Vegetation types in Shamwari include: Kowie Thicket, Bhisho Thornveld, Suurberg Quartzite Fynbos and Suurberg Shale Fynbos (Mucina \& Rutherford 2006). Shamwari is situated in the spring-dominant rainfall region of the province and receives about $550 \mathrm{~mm}$ of rainfall per annum (Low \& Rebelo 1996; Stone, Weaver \& West 1998). Permanent water is available in the semi-perrenial Bushman's River that flows through the reserve for $27.6 \mathrm{~km}$ and there are a number of small earth dams.

Carnivores that have been reintroduced to Shamwari include cheetah, leopard, lion, serval, African wild dog and brown hyaena. Historical records indicate that brown hyaenas had not been seen in the eastern Cape region since the 1960s (Hayward et al. 2007). During 2002, two adult male and four adult female brown hyaenas wild caught from Northern Cape Province farms were reintroduced to the reserve and, by 2004 , an estimated population of 15 hyaenas could be found in Shamwari. During 2007, seven adults and subadults were relocated from Shamwari to other Eastern Cape reserves. Despite this apparent success of reintroducing brown hyaenas into Shamwari, no detailed study on their diet has been conducted.

\section{Procedure}

Data on feeding observations of brown hyaenas documented by field guides whilst out on game drives with guests were collected between April 2008 and June 2009 (Figure 1). These recordings included the date, species being fed on, size and any other related information. Thirty-one fresh faecal scats were also collected from 11 latrines throughout the study area between April 2008 and May 2009 (Figure 2). Dried scats were placed into a nylon netting envelope and rinsed with warm water to loosen the hair and other objects trapped inside. The scats were dissected manually and all hair samples were removed. A representative sample was selected for analysis by inspecting all the hairs visually from each faecal scat and selecting at least one hair for each size, thickness, shape, colour and length (Maude 2005). This increased the chances of identifying all mammal species represented by hair in each faecal sample. A scale imprint was made of each hair sample by placing the hair onto a glass slide that was covered with liquid gelatine. Once the gelatine had dried, the hair was removed from the slide leaving the imprint of the hair's scale on the slide. Each hair sample was placed into the front section of a Pasteur pipette. Wax was melted and sucked up into the pipette and then dipped into cold water to solidify the wax. A cross-section of the hair was made by cutting the front end of the pipette into small slices with a surgical blade. The size and shape of the medulla and cortex of each cross-section, together with the scale imprints, were used to identify mammal species represented in each sample from reference material (Keogh 1983; Maude 2005; Perrin \& Campbell 1980). Samples from mammal species occurring in the reserve were also used to make up a reference key (see Appendix 1). Remains of insects, reptiles, fruit, bone, hair, feathers and any other objects were identified by manually sorting through the faecal scats.

Dietary diversity $(\mathrm{H})$ was calculated from the scats using the Brillouin index and the cumulative diversity $\left(\mathrm{H}_{\mathrm{k}}\right)$ was plotted against the number of scats to determine if the brown hyaenas diet had been adequately sampled (Glen \& Dickman 2006). The percentage occurrence of each prey item or species in the total number of scats was calculated as an indication of

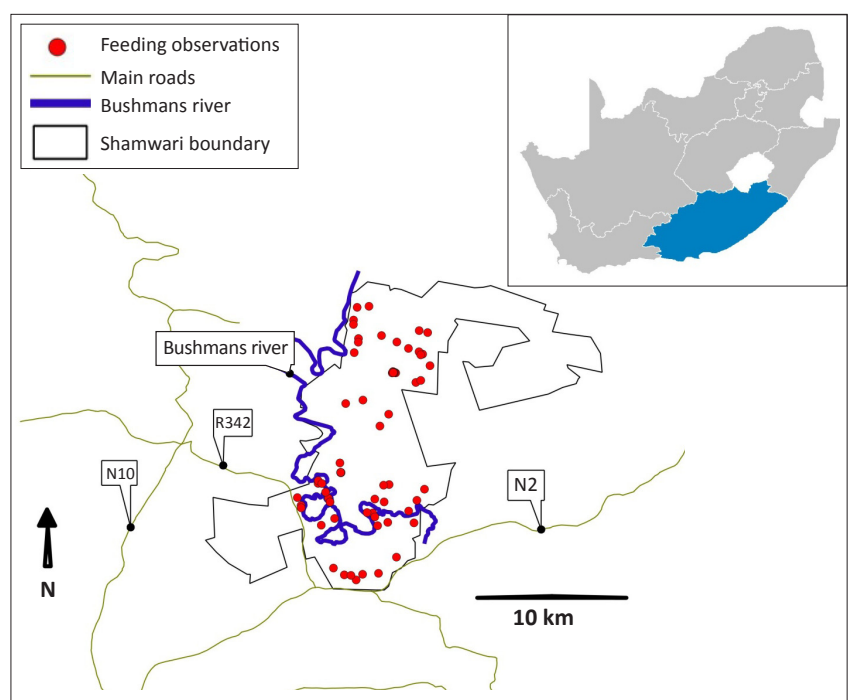

FIGURE 1: Locations of brown hyaena feeding observations by field guides in Shamwari Game Reserve, Eastern Cape Province during the study period, from April 2008 to June 2009.

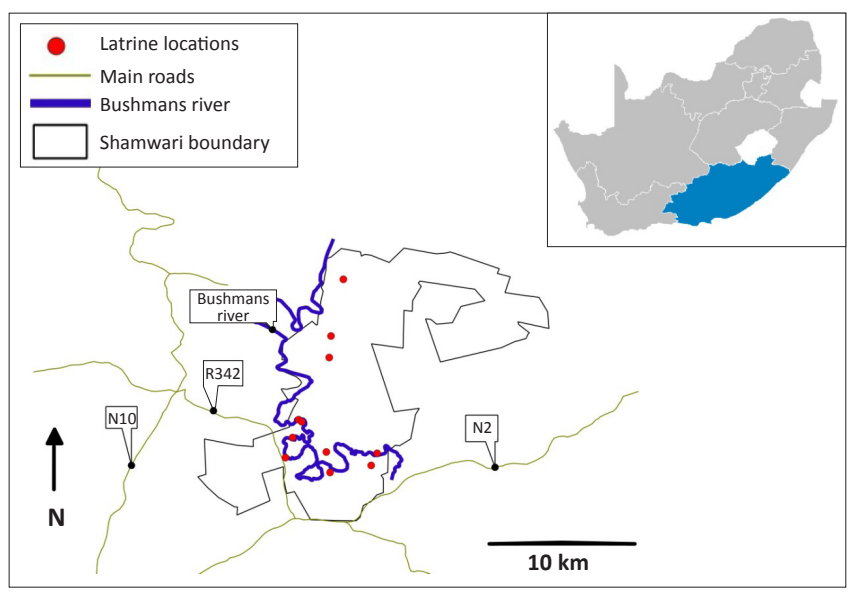

FIGURE 2: Locations of brown hyaena latrines used for faecal scat collection in Shamwari Game Reserve, Eastern Cape Province during the study period, from April 2008 to June 2009. 
how frequently the hyaenas fed on each dietary component (Loveridge \& Macdonald 2003). This was calculated by the number of scats containing a particular food item / total number of scats $\times 100$. The relative percentage occurrence (number of times a specific food item was encountered / total number of occurrences of all food items $\times 100$ ) indicated the importance of each food item to the overall diet (Loveridge \& Macdonald 2003). A 95\% confidence interval for both the percentage occurrence and the relative percentage occurrence were generated from 1000 bootstrap simulations (Andheria, Karanth \& Kumar 2007).

\section{Results}

Eighty-one feeding observations of brown hyaenas were made by field guides during the study period (Table 1). Fiftyseven $(70.00 \%)$ of the feeding observations were of brown hyaenas feeding on large mammals, of which $62.00 \%$ were of Ruminantia or Perrisodactyla. During the observations these larger items were always carried away from the carcass to be eaten elsewhere. On one occasion, a female brown hyaena was observed carrying a large piece of a gemsbok for over $3 \mathrm{~km}$ during 30 min of observation. Twelve observations (14.80\%) of brown hyena feeding on two white rhino carcasses that had been killed in a territorial dispute were made during the study period. A giraffe that had died of natural causes was observed being fed on by brown hyaenas eight times (9.88\%). Of the total observations, $11.00 \%$ (five blesbok, one kudu and three springbok) were kills that brown hyaenas had stolen from cheetah. Brown hyaenas were also observed to kill and eat one leopard tortoise (Geochelone pardalis) and three angulate tortoises (Chersina angulata).

The use of a cumulative Brillouin index $\left(\mathrm{H}_{\mathrm{k}}\right)$ indicated that the scat sample size of 31 scats was sufficient for brown hyaenas (Figure 3). We found a mean of 3.2 dietary categories per hyaena scat. Large mammal remains (>10 kg) were found in 30 of the 31 scats and were clearly the most important dietary component for brown hyaenas (Table 2). Five species of large mammals were identified from the scats, with kudu being the most frequent, representing $61.0 \%$ occurrence in the diet. Blesbok and bushbuck contributed $58.1 \%$ and $41.9 \%$ to the brown hyaena's diet, respectively. Plains zebra contributed $29.0 \%$ and warthog $12.0 \%$ to diet. Overall, at least 14 mammal species were found to be included in the hyaena's diet, as well as a variety insects, reptiles, birds and plant material.

\section{Discussion}

Brown hyaenas usually only hunt small mammals (Owens \& Owens 1978) and therefore the high number of large mammals being observed to be eaten and the hair found in the faecal scats was more than likely indicative of these prey items having been scavenged. This study confirms the findings of other such studies where remains in brown hyaena scats were mainly from members of the order Ruminantia (Burgener \& Gusset 2003; Van der Merwe et al. 2009). The low frequency of small species in this study may suggest that sufficient carrion is available due to the presence of other predators in the same area as the hyaenas, thereby

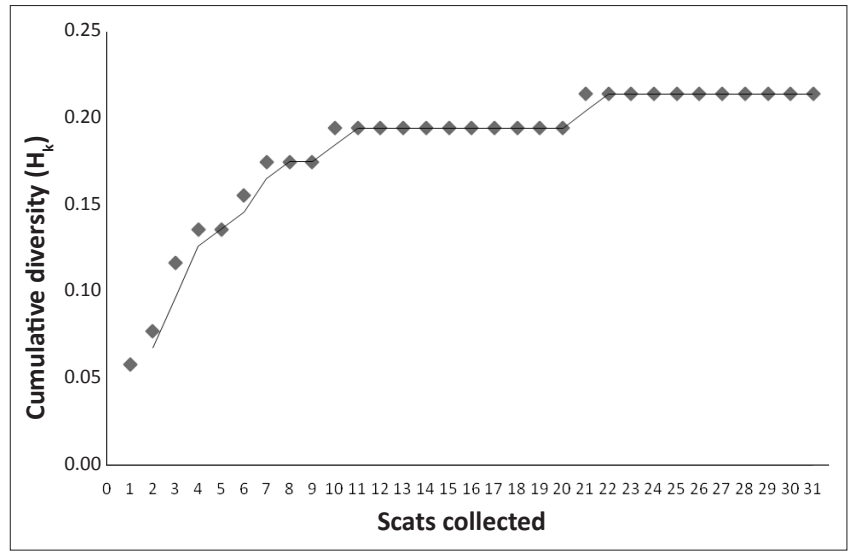

$n=31$ scats.

FIGURE 3: Species accumulation curve based on the cumulative Brillouin index for brown hyaena scat samples in Shamwari Game Reserve, Eastern Cape Province, South Africa.

TABLE 1: Feeding observations of brown hyaenas in Shamwari Game Reserve, Eastern Cape Province, South Africa.

\begin{tabular}{llcc}
\hline $\begin{array}{l}\text { Order or } \\
\text { suborder }\end{array}$ & Species & \multicolumn{2}{c}{$\begin{array}{c}\text { Percentage of feeding } \\
\text { observations ( } \boldsymbol{n}=\mathbf{8 1} \text { ) }\end{array}$} \\
\cline { 3 - 4 } & & $\mathbf{\%}$ & $\boldsymbol{n}$ \\
\hline Ruminantia & Black wildebeest (Connochaetes gnou) & 4.94 & 4 \\
& Impala (Aepyceros melampus) & 6.17 & 5 \\
& Springbok (Antidorcas marsupialis) & 3.70 & 3 \\
& Common duiker (Sylvicapra grimmia) & 1.23 & 1 \\
& Gemsbok (Oryx gazelle) & 2.47 & 2 \\
& Bushbuck (Tragelaphus scriptus) & 1.23 & 1 \\
& Blesbok (Damaliscus pygargus) & 8.64 & 7 \\
& Giraffe (Giraffa camelopardalis) & 9.88 & 8 \\
Perissodactyla & Kudu (Tragelaphus strepsiceros) & 8.64 & 7 \\
Suiformes & White rhinoceros (Ceratotherium simum) & 14.81 & 12 \\
Primates & Warthog (Phacochoerus africanus) & 4.94 & 4 \\
Carnivora & Chacma baboon (Papio ursinus) & 1.23 & 1 \\
\hline Testudines & Aardwolf (Proteles cristatus) & 2.47 & 2 \\
& Angulate Tortoise (Chersina angulata) & 3.70 & 3 \\
& Leopard tortoise (Geochelone pardalis) & 1.23 & 1 \\
\hline- & Unidentified vertebrate remains & 18.52 & 15 \\
\hline & Unidentified & 6.17 & 5 \\
\hline
\end{tabular}

TABLE 2: Diet of brown hyaenas in Shamwari Game Reserve, Eastern Cape Province, South Africa, as determined by faecal scats, expressed as the percentage occurrence and relative percentage occurrence.

\begin{tabular}{|c|c|c|c|c|}
\hline \multirow[t]{2}{*}{ Food item } & \multicolumn{2}{|c|}{ Percent occurrence } & \multicolumn{2}{|c|}{$\begin{array}{l}\text { Relative percent } \\
\text { occurrence }\end{array}$} \\
\hline & $\%$ & Range & Relative \% & Range \\
\hline Bushbuck (Tragelaphus scriptus) & 41.9 & $25.8-58.1$ & 9.0 & $4.9-13.9$ \\
\hline Blesbok (Damaliscus pygargus) & 58.1 & $38.7-74.2$ & 12.5 & 7.6-18.1 \\
\hline Kudu (Tragelaphus strepsiceros) & 61.3 & $42.0-77.4$ & 13.2 & $7.6-18.1$ \\
\hline Plains zebra (Equus quagga) & 29.0 & $12.9-45.2$ & 6.3 & $2.8-10.4$ \\
\hline Warthog (Phacochoerus africanus) & 12.9 & $3.2-25.8$ & 2.8 & $0.7-5.6$ \\
\hline Insects & 38.7 & $19.4-54.8$ & 8.3 & $4.2-13.2$ \\
\hline Freshwater crab & 3.2 & $0.0-9.7$ & 0.7 & $0.0-2.1$ \\
\hline Tortoise egg shell & 9.7 & $0.0-22.6$ & 2.1 & $0.0-4.8$ \\
\hline Unidentified hair & 58.1 & $41.9-74.2$ & 12.5 & $7.0-18.1$ \\
\hline Unidentified feathers & 6.5 & $0.0-16.1$ & 1.4 & $0.0-3.5$ \\
\hline Bone remains & 83.9 & $71.0-96.8$ & 18.1 & $11.8-25.0$ \\
\hline Plant remains & 51.6 & $32.3-67.7$ & 11.1 & $6.3-16.0$ \\
\hline Plastic & 9.7 & $0.0-22.6$ & 2.1 & $0.0-4.9$ \\
\hline
\end{tabular}

$n=31$. 
reducing the need for them to hunt. Although the occurrence of plant material found in the scats (52\%) is not as high as found in brown hyaenas living in arid areas (Mills \& Mills 1978), plant material is still an important component of the diet for brown hyaenas in Shamwari. Invertebrates that were consumed were more likely ingested during feeding off carcasses.

\section{Conclusion}

This article represents the first documented study of the dietary habits of brown hyaenas in Shamwari Game Reserve in the Eastern Cape. Further studies are currently underway to explore the feeding ecology and the influence of apex predators on the scavenging behaviour of the brown hyaenas in Shamwari Game Reserve and surrounding areas.

\section{Acknowledgements}

We thank Shamwari Game Reserve for permission to conduct the project. Nadia Muller, Dr Murray Stokoe and the Shamwari Rangers Department assisted with logistics of the project.

\section{Competing interests}

The authors declare that they have no financial or personal relationships that may have inappropriately influenced them in writing this article.

\section{Authors' contributions}

K.M. (Shamwari Game Reserve) was responsible for data collection and the initial draft of the article. K.S. (University of South Africa) was the project supervisor, analysed the data and wrote the final article.

\section{References}

Andheria, A.P., Karanth, K.U. \& Kumar, N.S., 2007, 'Diet and prey profiles of three sympatric large carnivores in Bandipur Tiger Reserve, India', Journal of Zoology, London 273, 169-175. http://dx.doi.org/10.1111/j.1469-7998.2007.00310.x

Burgener, N. \& Gusset, M., 2003, 'The feeding habits of brown hyaenas (Hyaena brunnea) on a game ranch in Limpopo Province, South Africa', African Zoology 38, 181-184.

Glen, A.S. \& Dickman, C.R., 2006, 'Diet of the spotted tailed quoll (Dasyurus maculatus) in eastern Australia: Effects of season, sex and size', Journal of Zoology, London 269, 241-248.

Goss, R.A., 1986, 'The influence of food source on the behavioural ecology of brown hyena in the Namib Desert', MSc thesis, Department of Zoology and Entomology, University of Pretoria.
Hayward, M.W., Adendorff, J., O'Brien, J., Sholto-Douglas, A., Bissett, C., Moolman, L.C. et al., 2007, 'The reintroduction of large carnivores to the Eastern Cape, South Africa: An assessment', Oryx 41, 205-214. http://dx.doi.org/10.1017/ South Africa: An ass
S0030605307001767

Hofmeyer, M. \& Van Dyk, G., 1998, 'Cheetah introductions to two North West parks: Case studies from Pilanesburg National Park and Madikwe Game Reserve', in B.L. Penzhorn (ed.), Cheetahs as game ranch animals, pp. 60-71, Wildlife Group of the South African Veterinary Association, Onderstepoort.

Keogh, H.J., 1983, 'A photographic reference system of the microstructure of the hair of southern African bovids', South African Journal of Wildlife Research 13, 89-132.

Kok, O.B. \& Nel, J.A.J., 2004, 'Convergence and divergence in prey of sympatric canids and felids: Opportunism or phylogenetic constraint?', Biological Journa of the Linnaean Society 83, 527-538. http://dx.doi.org/10.1111/j.10958312.2004.00409.x

Kuhn, B.F., Wiesel, I. \& Skinner, J.D., 2008, 'Diet of brown hyaenas (Parahyaena brunnea) on the Namibian coast', Transactions of the Royal Society South Africa 63(2), 150-159. http://dx.doi.org/10.1080/00359190809519219

Loveridge, A.J. \& Macdonald, D.W., 2003, 'Niche separation in sympatric jackals (Canis mesomelas and Canis adustus)', Journal of Zoology, London 259, 143-153. http:// dx.doi.org/10.1017/S0952836902003114

Low, A.B. \& Rebelo, A.G., 1996, Vegetation of South Africa, Lesotho, and Swaziland, Department of Environmental Affairs and Tourism, Pretoria.

Maude, G., 2005, 'The comparative ecology of the Brown Hyena (Hyaena brunnea) in the Makgadikgadi National Park and a neighbouring community cattle area in Botswana', MSc thesis, Department of Zoology and Entomology, University of Pretoria.

Mills, M.G.L., 1978, 'Foraging behaviour of the brown hyaena (Hyaena brunnea Thunberg, 1820) in the southern Kalahari', Zeitschrift fur tierpsychologie 48, 113141. http://dx.doi.org/10.1111/j.1439-0310.1978.tb00252.x

Mills, M.G.L., 1990, Kalahari hyenas: The comparative behavioral ecology of two species, Chapman \& Hall, London.

Mills, M.G.L. \& Hofer, H., 1998, Hyaenas - Status survey and conservation action plan, IUCN/SSC Hyaena Specialist Group, Gland.

Mills, M.G.L. \& Mills, E.J., 1978, 'The diet of the brown hyaena (Hyaena brunnea) in the southern Kalahari', Koedoe 21, 125-149. http://dx.doi.org/10.4102/koedoe. v21i1.968

Mucina, L. \& Rutherford, M.C. (eds.), 2006, 'The vegetation of South Africa, Lesotho and Swaziland', Strelitzia 19, South African National Biodiversity Institute, Pretoria.

O'Brien, J.W., 2004, 'Vegetation management units of Shamwari Game Reserve', MSc thesis, Terrestrial Ecology Research Unit, University of Port Elizabeth.

Owens, M.J. \& Owens, D.D., 1978, 'Feeding ecology and its influence on socia organization in brown hyaena (Hyaena brunnea, Thunberg) of the central Kalahar Desert', East Africa Wildlife Journal 16, 113-135.

Perrin, M.R. \& Campbell, B.S., 1980, 'Key to the mammals of the Andries Vosloo Kudu Reserve (Eastern Cape) based on their hair morphology, for use in predator scat analysis', South African Journal of Wildlife Research 10, 1-4.

Siegfried, W.R., 1984, 'An analysis of faecal pellets of the brown hyaena on the Namib coast', South African Journal of Zoology 19, 61.

Skinner, J.D., 1976, 'Ecology of the brown hyaena Hyaena brunnea in the Transvaa with a distribution map for southern Africa', South African Journal of Science 72 262-269.

Skinner, J.D. \& Chimimba, C.T., 2005, The mammals of the southern African subregion 3rd edn., Cambridge University Press, Cambridge. http://dx.doi.org/10.1017/ CBO9781107340992

Skinner, J.D. \& Van Aarde, R.J., 1981, 'The distribution and ecology of the brown hyaena Hyaena brunnea and spotted hyaena Crocuta crocuta in the central Namib Desert', Madoqua 12, 231-239.

Stone, A.W., Weaver, A.B. \& West, W.O., 1998, 'Climate and weather', in R.A. Lubke \& I. DeMoor (eds.), Field guide to the eastern and southern Cape coasts, pp. 41-49, University of Cape Town Press, Cape Town.

Van der Merwe, I., Tambling, C.J., Thorn, M., Scott, D.M., Yarnell, R.W., Green, M. et al., 2009, 'An assessment of diet overlap of two mesocarnivores in the North West Province, South Africa', African Zoology 44(2), 288-291.

Wiesel, I., 2010, 'Killing of Cape fur seal (Arctocephalus pusillus pusillus) pups by brown hyenas (Parahyaena brunnea) at mainland breeding colonies along the coastal Namib Desert', Acta Ethologica 13, 93-100 


\section{Appendix 1}

APPENDIX 1: Animal species other than brown hyaena that occur on Shamwari Game Reserve.

\section{Mammals}

Aardvark (Orycteropus afer)

Aardwolf (Proteles cristatus)

African wild cat (Felis silvestris)

African wild dog (Lycaon pictus)

Bat-eared fox (Otocyon megalotis)

Black footed cat (Felis nigripes)

Black rhinoceros (Diceros bicornis)

Black wildebeest (Connochaetes gnou)

Black-backed jackal (Canis mesomelas)

Blesbok (Damaliscus pygargus)

Blue duiker (Philantomba monticola)

Buffalo (Syncerus caffer)

Bushbuck (Tragelaphus scriptus)

Bushpig (Potamochoerus larvatus)

Cape clawless otter (Aonyx capensis)

Cape fox (Vulpes chama)

Cape grysbok (Raphicerus melanotis)

Cape hare (Lepus capensis)

Caracal (Caracal caracal)

Chacma baboon (Papio ursinus)

Cheetah (Acinonyx jubatus)

Common duiker (Sylvicapra grimmia)

Eland (Tragelaphus oryx)

Elephant (Loxodonta africana)

Gemsbok (Oryx gazella)

Giraffe (Giraffa camelopardalis)

Hedgehog (Atelerix frontalis)

Hippopotamus (Hippopotamus amphibious)

Honey badger (Mellivora capensis)
APPENDIX 1 (Continues...): Animal species other than brown hyaena that occur on Shamwari Game Reserve.

Impala (Aepyceros melampus)

Kudu (Tragelaphus strepsiceros)

Large-spotted genet (Genetta tigrina)

Leopard (Panthera pardus)

Lion (Panthera leo)

Mountain reedbuck (Redunca fulvorufula)

Plains zebra (Equus quagga)

Porcupine (Hystrix africaeaustralis)

Red hartebeest (Alcelaphus buselaphus)

Rock hyrax (Procavia capensis)

Scrub hare (Lepus saxatilis)

Serval (Leptailurus serval)

Small grey mongoose (Galerella pulverulenta)

Small-spotted genet (Genetta genetta)

Springbok (Antidorcas marsupialis)

Springhare (Pedetes capensis)

Steenbok (Raphicerus campestris)

Striped polecat (Ictonyx striatus)

Striped weasel (Poecilogale albinucha)

Suricate (Suricata suricatta)

Vervet monkey (Cercopithecus pygerythrus)

Warthog (Phacochoerus africanus)

Water mongoose (Atilax paludinosus)

Waterbuck (Kobus ellipsiprymnus)

White rhinoceros (Ceratotherium simum)

Yellow mongoose (Cynictis penicillata)

Reptiles

77 species

Tortoise

4 species 